\title{
Standing Height and Its Estimation Utilizing Length of Hand Measurements of Kosovan Adolescents of Both Genders
}

\author{
Fitim Arifi ${ }^{1,2 *}$ \\ ${ }^{1}$ Department of Physical Culture, Sport and Recreation, Kolegji University, Kosovo \\ ${ }^{2}$ Faculty for Sport and Physical Education, University of Tetova, North Macedonia \\ *Corresponding author: Fitim Arifi, Department of Physical Culture, Sport and Recreation, Kolegji University, Kosovo
}

\section{ARTICLE INFO}

Received: 蔧 March 06, 2020

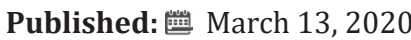

Citation: Fitim Arifi. Standing Height and Its Estimation Utilizing Length of Hand Measurements of Kosovan Adolescents of Both Genders. Biomed J Sci \& Tech Res 26(4)-2020. BJSTR. MS.ID.004376.

\begin{abstract}
The anthropometric dimensions of the human body and their inter-relationships have awakened the curiosity of many authors around the world undertaking research in this regard by comparing relations between different races, as well as within a population but from different geographical regions. The purpose of this research was to estimate the average body height of Kosovan adolescents of both genders from the length of the hand. This research included a sample of 1,623 Kosovan high school graduates (830 males and 793 females). Measurements of body height and the length of the hand were performed with reference to the protocol of International Association for the Advancement of Kinanthropometry. The results for body height and length of the hand were analyzed by means of the arithmetic mean (SD) and a simple correlation coefficient, while T-test analysis was used for differences between the two genders and linear regressive analysis assessed body height based on length of hand measurements. The results obtained in this paper have shown that body height can be estimated from the length of the hand, which reliably predicts body height for both genders.
\end{abstract}

\section{Introduction}

The anthropometric dimensions of the human body and their inter-relationships have awakened the curiosity of many authors around the world undertaking research in this regard by comparing relations between different races, as well as within a population but from different geographical regions [1-5]. One of the dimensions of the body that has been most frequently addressed by research in relation to other anthropometric parameters is body height, which is widely recognized as one of the most significant anthropometric measures whose values can be used for various purposes, such as assessing children's growth and development, nutrition, overweight, talent identification and energy consumption, thereby underlining the importance of accurately recognizing these values [6-8]. However, body height is not always possible to measure in the traditional way, for example, in cases where an individual has some form of paralysis, fractures, amputations, scoliosis, kyphosis, osteoporosis, hormonal imbalances and various kinds of pain [9-12]. In such cases, we need to estimate relative body height using other anthropometric parameters as reliable predictors, such as arm span, which has been established by many authors to be one of the best predictors of body height compared to, among others, sitting height, hand length, spine length, tibia length, foot length and sternum length. Research indicates that the relationships between body height and other anthropometric parameters are different and vary from race to race, ethnicity to ethnicity, and region to region [4,9,10,13-18]. According to a study conducted by Quanjer et al. [7], body height relative to other anthropometric parameters varies non-linearly, based on the age between males and females. It is especially interesting to note that a number of scientific studies has confirmed that people who are tall suffer more from heart disease, as well as some types of cancer, earlier damage to the joints and spine, etc., but, in other cases, tall people also enjoy more privileges in society, usually have higher social positions, are more successful at school and in a considerable range if sports and sports-related [2,5]. 
Kosovo is in the central part of the Western Balkans. Roads across Kosovo connect the Adriatic and the Aegean within the interior of the Balkan Peninsula. Its borders are shared with Albania (112 km), Macedonia (160 km), Montenegro (76 km) and Serbia (366 km). Kosovo's borders with neighbouring countries mainly cross mountains and are of a natural character: to the west of Kosovo, the border is with Bjeshket e Nemuna; to the south, it is with Sharr Mountain and Pashtrik; and, to the north and northeast, it is with Kopaonik. The eastern perimeter of the Kosovo Basin is lower and thus waters flow into the South Morava Valley and Toplica. The south-western part of Dukagjini, between Pashtrik and Koritnik, is also lower and the White Drin flows there. Mountains make up about $63 \%$ of the territory of Kosovo and are divided into several groups: suburban and central, and high, middle and low mountains. The Dinaric Mountains belong to the western part of Kosovo. The Inner Dinaric Mountains include Mount Mokna and the Mali i Thatë and the Bjeshkët e Nemuna Mountains. Kosovo's climate is conditioned by geographical location. Extending through the medium latitude, Kosovo's climate is conditioned by the amount of sunshine, and its proximity to the Adriatic Sea, the Vardar Valley, and the opening to the north, where the altitude averages $400 \mathrm{~m}$ [19].

Based on the available data, Kosovo lies within several different geographical regions and its population belongs to the Central
Dinaric Zone; thus, it is highly important to conduct a professional study that would provide a morphometric estimate of the entire population. With different geographical and administrative regions (Prishtina, Mitrovica, Peja, Gjakova, Prizreni, Ferizaji \& Gjilani), Kosovo has a territory of $10,887 \mathrm{~km}^{2}$ and 1,907,592 inhabitants (July 2018 estimate), whose average age is 29.6 years, while $50.34 \%$ are male and $49.66 \%$ female. There are some ethnic groups in Kosovo that are composed of: Albanians (92.9\%), Bosnians (1.6\%), Serbs (1.5\%), Turks (1.1\%), Ashkali (0.9\%), Egyptian $(0.7 \%)$, Gorani $(0.6 \%)$ and Roma $(0.5 \%)$, with other/unspecified at $0.2 \%$. A map of Kosovo is shown in Figure 1. A large number of studies has been conducted worldwide on body height to arm span ratios involving anthropometric parameters, using similar samples to the adolescent population of Kosovo in general $[3,20,21]$, as well as on body height to foot length ratios [1], body height to sitting height ratios $[7,22]$ and body height to tibia length ratios [23]. Based on the above research, it is critical for the population of Kosovo to have accurate information as well as body height to length of hand ratios, which are of great importance to medicine, sports, anthropology and other fields. Therefore, the first aim of this research is to examine the average body height of Kosovan adolescents for both genders, as the authors believe that Kosovo's population can reach full potential for the Dinaric race, while the second aim is to examine body height for both genders in Kosovo and its relationship to hand length.

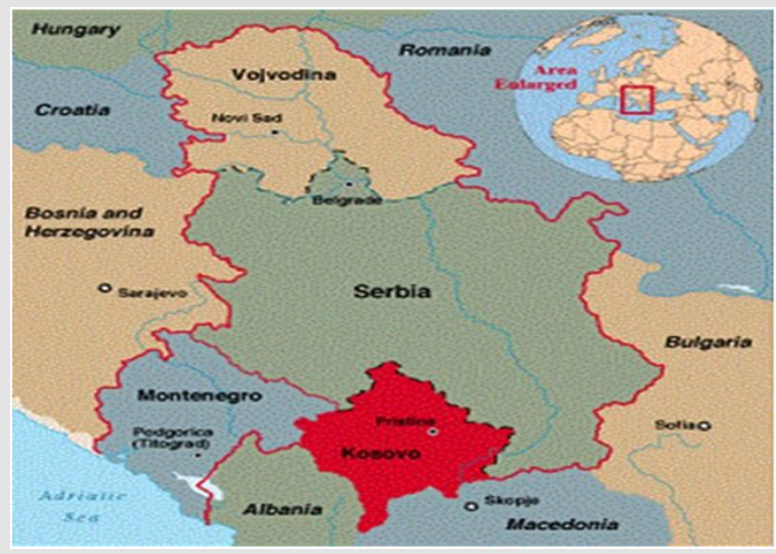

Figure 1: Geographical Location of the Republic of Kosovo.

\section{Materials and Methods}

This research on the population of Kosovo included a sample of 1,623 high school graduates from seven official Kosovo administrative regions: Pristina, Mitrovica, Peja, Gjakova, Prizren, Ferizaj \& Gjilan, of whom 830 were male students with a mean age of $18.45 \pm 0.45$ and 793 were female students with a mean age of $18.24 \pm 0.43$. We chose to obtain measurements from graduates because, being 18 years old, it was expected that, at the time of measurement, body growth and development had been completed for both genders and maximum body height had been reached. It is also worth noting that the sampling criterion was random on the day the measurements were made, but all students were included, regardless of whether they had any physical disabilities and/or and were permanent residents in Kosovo. The measurements were made by experts from the Institute of Sport Anthropology and the National Centre for Sport Medicine, both in Pristina.

Measurements of body height and hand length were performed by reference to the protocol of the International Association for the Advancement of Kinanthropometry [24]. Whereas students' age data were obtained at the time of the measurements and each person's age was calculated from his/her date of birth and the date the measurements were made. The results for body height and hand length were calculated using the SPSS version 25.0 mathematical package for everyone. The arithmetic mean (SD) was calculated for 
both genders, while T-test analysis was performed regarding the two anthropometric variables, differences between body height and hand length for each sex group and between genders. The ratios between body height and length of hand were determined via Pearson's correlation coefficient with a 95 per cent confidence limit. Meanwhile, to determine the extent to which the length of the hand can predict body height, linear regressive analysis was employed. The significance of the statistical coefficient was set at the level of $\mathrm{p}<0.05$.

\section{Results}

A summary of the results for the anthropometric measurements of both genders are presented in Table 1 . The arithmetic mean of body height in males is $179.52 \pm 5.96$ centimetres and the length of the hand is $19.14 \pm 0.86$ centimetres, while, in females, the arithmetic mean is $165.72 \pm 4.93$ centimetres for body height and $17.46 \pm 0.74$ centimetres for hand length. Differences between males and females in the case of anthropometric measurements of body height and length of hand were statistically significant at (males: $\mathrm{t}=20.876, \mathrm{p}<0.000$; females: $\mathrm{t}=18.626, \mathrm{p}<0.000$ ). The simple correlation coefficient and analysis of the 95 per cent confidence interval between anthropometric measurements are presented in Table 2. The correlations between body height and the length of the hand are significant $(\mathrm{p}<0.000)$ and the correlations between the two anthropometric variables are good for both genders (males: 0.587; females: 0.552). The results of the linear regressive analysis are presented in Table 3 . The results of the regression coefficient are high (males: 0.587; females: 0.552), while the results of body height prediction for Kosovan adolescents from the length of the hand for both genders are as follows: males: $t=20.876, p<0.000$; females: $t=18.626, p<0.000$. These results are confirmed by the coefficient of determination, denoted as R-squared (\%), for males at 34.5 and for females at 30.5. The associations between body height measurements and length of the hand among the above models is sketched as a scatter diagram.

Table 1: Anthropometric measurements for both genders.

\begin{tabular}{|c|c|c|}
\hline Subjects & $\begin{array}{c}\text { Standing Height Range } \\
\text { (Mean } \pm \text { SD) }\end{array}$ & $\begin{array}{c}\text { Length of Hand Range } \\
\text { (Mean } \pm \text { SD) }\end{array}$ \\
\hline Male & $\begin{array}{c}161.4-198.8 \\
(179.52 \pm 5.96)\end{array}$ & $\begin{array}{c}15.6-24.6 \\
(19.14 \pm 0.86)\end{array}$ \\
\hline Female & $\begin{array}{c}153.3-185.0 \\
(165.72 \pm 4.93)\end{array}$ & $\begin{array}{c}15.3-20.1 \\
(17.46 \pm 0.74)\end{array}$ \\
\hline
\end{tabular}

Table 2: Correlation between body height and hand length of the study subjects.

\begin{tabular}{|c|c|c|c|}
\hline Subjects & $\begin{array}{c}\text { Correlation } \\
\text { Coefficient }\end{array}$ & $\begin{array}{c}\mathbf{9 5 \%} \\
\text { Confidence } \\
\text { Interval }\end{array}$ & $\begin{array}{c}\text { Significance } \\
\mathbf{p} \text {-Value }\end{array}$ \\
\hline Male & 0.587 & $0.469-0.585$ & $<0.000$ \\
\hline Female & 0.552 & $0.494-0.610$ & $<0.000$ \\
\hline
\end{tabular}

Table 3: Results of linear regression analysis where hand length predicts body height.

\begin{tabular}{|c|c|c|c|c|c|}
\hline Subjects & $\begin{array}{c}\text { Regression } \\
\text { Coefficient }\end{array}$ & $\begin{array}{c}\text { Standard } \\
\text { Error } \\
\text { (SE) }\end{array}$ & $\begin{array}{c}\text { R-Square } \\
\text { (\%) }\end{array}$ & t-Value & p-Value \\
\hline Male & 0.587 & 4.827 & 34.5 & 20.876 & 0.000 \\
\hline Female & 0.552 & 4.115 & 30.5 & 18.626 & 0.000 \\
\hline
\end{tabular}

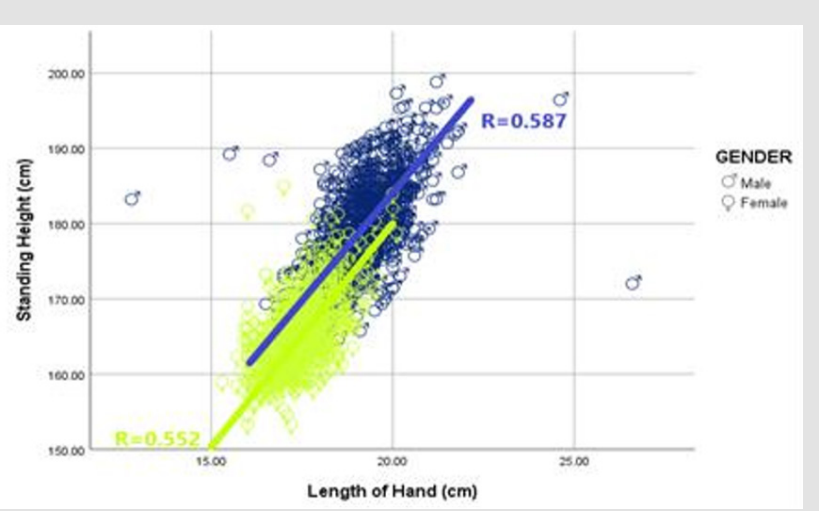

Figure 2: Scatter Diagram and Relationship between Length of Hand Measurements and Body Height among Both Genders.

\section{Discussion}

To estimate body height from the length of the hand, we used some specific equations for males and females: first, the arithmetic mean for males and females was found through descriptive analysis of both variables, then the difference between males and females was determined using the T-test for independent samples, while the relation between the two variables as well as the prediction of body height from the length of the hand was evaluated with a regression coefficient using linear regression analysis. The data from this study enrich extant information on the population of Kosovo and could become part of the researched models in Europe and of the world population. Through this study, it can be established that adolescents from Kosovo are ranked very high in the world, with an average body height of $179.52 \pm 5.96$ centimetres, while representing $5.1 \%$ of the population over 190.00 centimetres in height [3]. This information can be compared to the situation in other countries in the region, Europe and around the world. Compared to countries in the region such as Macedonia, Kosovans are taller than those with an average height of 178.10 centimetres [5], while only 2.7 per cent of the population are more than 190.00 centimetres in height, representing 1.5 per cent of the French population [25].

However, Kosovans are not taller than Montenegrins, whose height is 183.36 centimetres on average [4], representing 18.2 per cent, compared to 20 per cent in the Netherlands, while the highest density of those over 190.00 centimetres is found in the population of the Dinaric Alps at 28 per cent [25]. In addition, female Kosovan 
adolescents are among the world's tallest populations with an average height of $165.72 \pm 4.93$ centimetres and a density of less than one per cent $(0.8 \%)$ of the population with a height above 180.00 centimetres [3]. Compared to countries in the region, such as Macedonia, Kosovans are taller than those in Macedonia with an average height of 164.58 centimetres [5] while their density is less than one per cent of those over 180.00 centimetres tall. But a slightly larger difference is found in the case of females from the Netherlands, having a height of 168.8 centimetres [26] or with females from Montenegro averaging 168.3 centimetres [4]. This paper is still not complete, because the other main aim was to estimate body height from the length of the hand and the links between them in the case of measurements for both genders among Kosovan adolescents.

Besides arm span, sitting height, foot length and tibia length $[3,7,22,27]$ have proven to be good predictors of body height in our study. Hand length, using deterministic equations has been shown to be reliable predictors, especially about the body height of Kosovan adolescents of both genders. Research by different authors has revealed that the dimensions of hand length vary from race to race and therefore the formulas that can be applied to one ethnic group are not necessarily applicable to others, on account of genetic, environmental and socioeconomic factors [28-30]. That said, some studies have demonstrated that differences can also be individual $[31,32]$. This study confirms the existence of differences in body height and hand length which are statistically significant between males and females, where the mean length of hand was $19.14 \pm 0.86$ centimetres for males and $17.46 \pm 0.74$ centimetres for females, and the difference was significant at the $\mathrm{p}<0.000$ level; this has also been validated by other authors [33-36]. Relationships between body parameters have been the focus of years of research for many anthropologists, which is why we have also tried to validate the correlation between body length and the length of the hand.

The present study reports high values for the correlation coefficient between body length and hand length measurements for both genders, while the correlation between body length and hand length for males is ( $r=0.587)$ and, for females, it is $(r=0.552)$; these results are comparable to those found in other studies from Europe and the rest of the world. Recent studies have presented results similar to those in the study from Wakode et al. [37] who found a high correlation between body height and male hand length with a value of $(r=0.699)$ and female hand length with a value of $(r$ $=0.693$ ). Similar correlation values between body height and hand length in the Egyptian population have been found by Muhammad (2013), who found a correlation between these two parameters of $(r=0.525)$ for males and $(r=0.697)$ for females. Comparable findings for stature and hand length have been reported by Moorthy and Zulkfly (2014), with values of $(r=0.604)$ for males and $(r=$ 0.630 ) for females. Uhrova et al. [12], in her study on Slovak youth, observed a correlation between body height and hand length of $\mathrm{r}$
$=0.630$ ) for males and ( $\mathrm{r}=0.580$ ) for females, and Ozalsan et al. (2012) found a correlation between body height and hand length of $(r=0.578)$ for males and $(r=0.309)$ for females, while Patel et al. [36] found higher values between body height and the length of male hands $(\mathrm{r}=0.806)$ [38-44].

\section{Conclusion}

On account of the models applied in this paper, it is evident that body height showed a high correlation with hand length and confirmed that body height can be estimated from the length of the hand among Kosovan adolescents. The limitation of this study is that the male and female Kosovan adolescents included in this study were born in 1998, which was a period of war in Kosovo, when half the population were displaced from their homes. Their lives have been lived under difficult socioeconomic conditions. As the authors of this paper, we conclude that the average stature of Kosovan boys and girls has not yet reached its full maximum genetic potential and that it is expected that future generations will achieve greater body height and be among the tallest populations the world. It is therefore necessary to consider different models for population research in Kosovo, based on each region and both genders.

\section{Conflict of Interest}

The author declares no conflict of interest.

\section{References}

1. Arifi F, Gardasevic J, Masanovic B (2018) Relationship between foot length measurements and body height: A prospective regional study among adolescents in Central region of Kosovo. Sport Mont Jour 16(3): 75-79.

2. Arifi F (2018) Body Height of Adolescents in kosovo and ist relationship with other anthropomtric measures as a potential predictor. $\mathrm{PhD}$ Dissertation, University of Montenegro.

3. Arifi F, Bjelica D, Sermaxhaj S, Gardasevic J, Kezunovic M, et al. (2017) Stature and its Estimation Utilizing Arm Span Measurements in Kosovan Adults: National Survey. International Journal of Morphol 35(3): 11611167.

4. Bjelica D, Popović S, Kezunovic M, Petkovič J, Jurak G, et al. (2012) Body height and its estimation utilizing arm span measurements in Montenegro adults. Anthropological Notebooks 18(2): 69-83.

5. Popovic S, Bjelica D, Georgiev G, Krivokapic D, Milasinovic R (2016) Body Height and its Estimation Utilizing Arm Span Measurements in Macedonian Adults. Anthropologist 24(3): 737-45.

6. Datta Banik S (2011) Arm span as a proxy measure for height and estimation of nutritional status: A study among Dhimals of Darjeeling in West Bengal India. Annals of Human Biology 38(6):728-35.

7. Popovic S (2018) Arm-span measurement as an alternative estimation of true height in Montenegrin young adults of both sexes: A national survey. Anthropological Notebooks 24(1): 53-67.

8. Rexhepi A, Brestovci B, Isufi I (2018) Normative Values of Some Morphometric Variables for Kosovo Albanian Population Aged $06>70$ Years Old. International Journal of Morphology 36(2):592-597.

9. Memishi SH, Ameti V, Arifi F (2019) Standing Height and Its Estimation Utilizing Length of Hand Measurements of Both Gender Adolescents from North Region of Kosovo; District of Mitrovica. Journal of Education, Health and Sport 9(12): 11-18.

10. Mohanty SP, Babu SS, Nair NS (2001) The use of arm span as a predictor 
of height. A study of South Indian women. Journal of Orthopedics Surgery 9(1): 19-23.

11. Quanjer PH, Capderou A, Mazocioglu MM, Aggarwal A, Popovic S, et al. (2014) All-age relationship between arm span and height in different ethnic groups. European Respiratory Journal 44(4): 905-12.

12. Ter Goon D, Toriola AT, Musa DI, Akusu S (2011) The relationship between arm span and stature in Nigerian adults. Kinesiology 43(1): 38-43.

13. Agnihotri AK, Purwar B, Googoolybe K, Agnihotri S, Jeebun N (2007) Estimation of stature by foot length. Journal Forensic Legal Med 14(5): 279-283.

14. Brown J K, Feng J Y, Knapp T R (2002) Is self-reported height or arm span a more accurate alternative measure of height. Clinical Nursing Research 11(4): 417-32.

15. Campobasso C P, Di-Vella G, Introna F (1998) Using scapular measurements in regression formulae for the estimation of stature. Bollettino della Societa Italiana Di Biologia Sperimentale 74(7-8):75-82.

16. De Lucia E, Lemma F, Tesfaye F, Demisse T, Ismail S (2002) The use of armspan measurement to assess the nutritional status of adults in four Ethiopian ethnic groups. European Journal of Clinical Nutrition 56(2): 91-5.

17. Reeves SL, Varakamin C, Henry CJ (1996) The relationship between arm-span measurement and height with special reference to gender and ethnicity. European Journal of Clinical Nutrition 50(6): 398-400.

18. Steele M F, Chenier T C (2009) Arm-span, height and age in black and white women. Annals of Human Biology 17(6): 533-41.

19. Çavolli R (1997) Gjeografia Regjionale e Kosoves, Enti i teksteve dhe i mjeteve mësimore i Kosovës, Prishtinë.

20. Arifi F, Sermaxhaj S, Zejnullahu-Raçi P, Alaj I, Metaj Z (2017) Stature and its estimation utilizing arm span measurements of both gender adolescents from northern region in Kosovo. Acta Kinesiologica 11(1): 49-52.

21. Arifi F (2017) Stature and its estimation utilizing arm span measurements of both gender adolescents from southeast region in Kosovo. Sports Science 10(1): 92-95.

22. Gardasevic J, Masanovic B, Arifi F (2018) Relationship between tibia length measurements and standing height: A prospective regional study among adolescents in southern region of Kosovo. Sport Mont Journal 16(3): 51-55

23. Masanovic B, Gardasevic J Arifi F (2019) Relationship between foot length measurements and body height: A prospective regional study among adolescents in northern region of Kosovo. Anthropologie 57(2): 227-233.

24. Marfell Jones M, Olds T, Stew AD, Carter JEL (2006) International standards for anthropometric assessment. Potchesfstroom: International Society for the Advancement of Kinanthropometry.

25. Pineau JC, Delamarche P, Bozinovic S (2005) Average height of adolescents in the Dinaric Alps. Comptes Redus Biologies 328(9): 841846.

26. (2016) Statistics Netherland. Lifestyle, preventive screening; sex, age, 2015. Retrieved on March 15, 2016.

27. Popovic S, Gardasevic J, Masanovic B, Arifi F, Bjelica D (2017) Standing Height and its Estimation Utilizing Foot Length Measurements in Adolescents from Western Region in Kosovo. Sport Mon Journal 15(3):37.

28. Lukpata P, Ojim EO, Esemonu U G, Okori SO, Egwu AO, et al. (2015) Stature estimation from hand dimensions in Bekwara ethnic group of cross River State, Nigeria. The International Journal of Science and Technoledge 3(9): 267-270.

29. Krishan K, Sharma A (2007) Estimation of stature from dimensions of hands and feett in a north Indian population. Journal of Forensic and Legal Medicine14(6): 327-332.

30. Malina RM, Little BB, Stern MP, Gaskill SP, Hazuda HP (1983) Ethnic and social class differences in selected anthropometric characteristics of Mexican American and Anglo adults: the San Antonio heart study. Hum Biol 55(4): 867-83

31. Dubois L, Ohm Kyrik, Girard M, Tatone-Tokuda F, Perusse D, et al. (2012) Genetic and environmental contributions to weight, height and BMI from birth to $19 y$ rs of age: an international study over 12,000 twin pairs. Plos One 7(2): 30153.

32. Silventoinen K, Bartels M, Posthuma D, Estourgie-Van B, Willem G (2007) Genetic regulation of growth in height and weight from 3 to 12 years of age: a longitudinal study of dutch twin Children. Twin Res Hum Genet $10(2): 354-363$

33. Agnihotri AK, Agnihotri S, Jeebun N, Googoolye K(2008) Prediction of stature using hand dimensions. Journal Forensic Legal Med 15(8): 479482.

34. Rastogi P, Nagesh K R, Yoganarasimha K (2008) Estimation of stature from hand dimensions of north and south Indians. Legal Medicine (Tokyo) 10(4): 185-189.

35. Ilayperuma I, Nanayakkara G, Palahepitiya NA (2010) A Model for the Estimation of Personal Stature from the Length of Forearm. International Journal of Morphology 28(4): 1081-1086.

36. Numan L, Idris J, Zirahei DS, Amaza M, Dalori L (2013) Prediction of stature from hand anthropometry: A Comparative study in the three major ethnic groups in Nigeria. Br J Med Med Res 3(4): 1062-1073.

37. Uhrova P, Benus R, Masnicova S, Obertova Z, Kramarova D, et al. (2015) Estimation of stature using hand and foot dimensions in Slovak adults. Legal medicine 17(2): 92-97.

38. Wakode NS, Wakode SL, Ksheersagar DD, Tajane VD, Jachak AN (2015) Prediction of Stature based on Measurement of Hand Lengthin Maharashtra Region. Indian Journal of Clinical Anatomy and Physiology 2(3): 13-135.

39. Mohamed M H (2013) Measurement of Foot and Hand Dimensions andtheir Correlation with Height in Adult Upper Egyptians. Al_Azhar Assiut Medical Journal 10(4): 300-318.

40. Moorthy TN, Zulkifly NR B (2014) Regression Analysis for Stature Determination from Hand Anthropometry of Malaysian Malays for Forensic Investigation. Sri Lanka Journal of Forensic Medicine, Science \& Law 5(2): 8-15.

41. Patel P N, Tanna JA, Kalele SD (2012) Correlation between hand length and various anthropometric parameters. International Journal of Medicine Toxiology and Forensic Medicine 2(2): 61-63.

42. Popovic S, Bjelica D, Tanase G D, Milasinovic R (2015) Body Height and Its Estimation Utilizing Arm Span Measurements in Bosnian and Herzegovinian Adolescents. Montenegrin Journal of Sports Science and Medicine 4(1): 29-36.

43. Popovic S, Arifi F, Bjelica D (2017) Standing Height and its Estimation Utilizing Foot Length Measurements in Kosovan Adults: National Survey. International Journal of Applied Exercise Physiology 6(2): 1-7.

44. Arifi F, Memishi SH, Ameti V (2020) Stature and Its Estimation Utilizing Length of Hand Measurements of Both Gender Adolescents from South region of Kosovo; District of Prizren. International Journal of Applied Exercise Physiology 4(1): 1-7. 
ISSN: 2574-1241

DOI: $10.26717 /$ BJSTR.2020.26.004376

Fitim Arifi. Biomed J Sci \& Tech Res

(C) (P) This work is licensed under Creative

Submission Link: https://biomedres.us/submit-manuscript.php

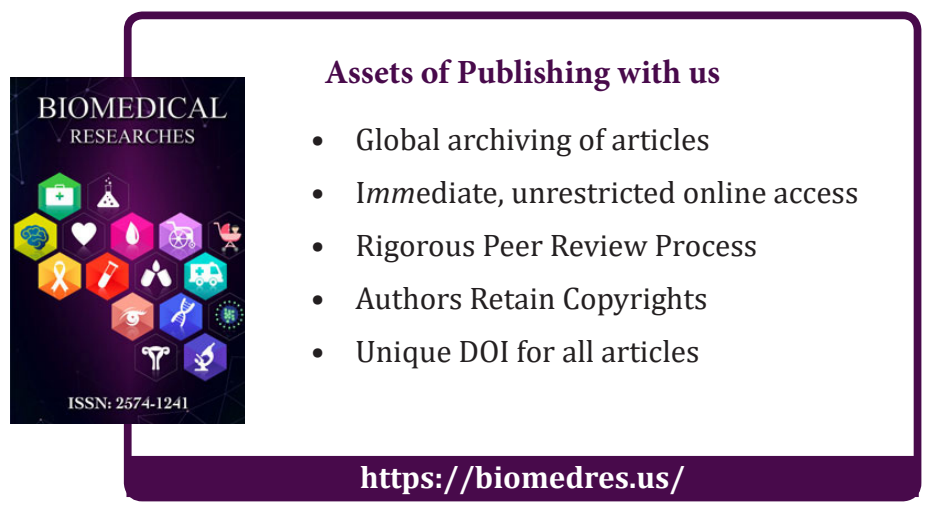

